\title{
KENYAMANAN VISUAL MELALUI PENCAHAYAAN ALAMI PADA KANTOR (STUDI KASUS GEDUNG DEKANAT FAKULTAS TEKNIK UNIVERSITAS BRAWIJAYA MALANG)
}

\author{
Jusuf Thojib1, Muhammad Satya Adhitama² \\ Alamat Email penulis : jusuf_12@yahoo.com
}

\author{
1 Jurusan Arsitektur/Fakultas Teknik, Universitas Brawijaya \\ ${ }^{2}$ Jurusan Arsitektur/Fakultas Teknik, Universitas Brawijaya
}

\begin{abstract}
ABSTRAK
Kantor sebagai area kerja membutuhkan tingkat kenyamanan yang memadai agar pengguna di dalamnya dapat melakukan aktivitas dengan lancar dan memiliki produktivitas kerja yang baik. Kenyamanan tidak hanya bergantung pada temperatur dalam ruang, radiasi matahari yang masuk, kualitas udara, dan penghawaan,namun juga ditentukan oleh kualitas pencahayaan. Indonesia dengan kondisi kaya sinar matahari sepanjang tahun selayaknya menempatkan pencahayaan alami sebagai prioritas dalam rancangan; selain sebagai upaya tanggap lingkungan, pemanfaatannya juga dapat menghemat konsumsi energi bangunan.Penelitian ini bertujuan mengevaluasi kenyamanan visual dari penerapan pencahayaan alami pada kantor dengan studi kasus Gedung DekanatFakultas Teknik Universitas Brawijaya (FT UB) Malang.Metode penelitian deskriptif dan korelasional, berupaya memadukan hasil pengamatan (pengamatan yang dilakukan berupa pengukuran iluminasi dengan luxmeter, simulasi kontur pencahayaan alami, identifikasi elemen-elemen yang mempengaruhi pencahayaan alami) dengan persepsi pengguna untuk mendapatkan gambaran kenyamanan visual serta karakteristik rancangan pencahayaan alami pada gedung Dekanat FT UB sehingga pada tahap selanjutnya dapat diberikan rekomendasi untuk pencapaian kenyamanan visual yang lebih baik.
\end{abstract}

Kata kunci : kantor, kenyamanan visual, pencahayaan alami

\section{ABSTRACT}

Office as a work area requires an adequate level of comfort, so that users can carry out activities smoothly and has a good working productivity. Convenience is not only dependent on the temperature in the chamber, incoming solar radiation, air quality, and weather quality, but is also determined by the quality of the lighting. Indonesia with rich conditions year-round sunshine should put natural lighting as a priority in the design ; aside as environmental response efforts , utilization also can save energy consumption of building. research was designed to evaluate the visual comfort of the application of natural lighting in the office building, on case study Dekanat Fakultas Engineering University Brawijaya ( UB FT ) Malang. method descriptive and correlational research, seeks to combine the observations ( observations made in the form of illumination with luxmeter measurement, simulation contours of natural lighting, the identification of the elements that affect the natural lighting ) with the perception of the user to get an overview of visual comfort and design characteristics of natural lighting in buildings FT UB so as at a later stage can be given recommendations for the achievement of better visual comfort

Keywords: office, visual comfort, natural lighting 


\section{Pendahuluan}

Bangunan adalah salah satu pengkonsumsi energi terbesar, World Green Building Council menyebutkan bahwa sektor konstruksi menyerap 30-40\% total energy dunia (Kerr, 2008). Oleh karenanya, penerapan konsep hemat energi dari sektor bangunan akan dapat memberikan efek signifikan pada keberlanjutan ketersediaan energi. Salah satu upaya penghematan energi pada bangunan adalah dengan optimalisasi desain untuk mewadahi penggunaan potensi alam, termasuk di dalamnya pencahayaan. Studi pada bangunan kantor di Hawaii menyebutkan bahwa $27 \%$ dari total konsumsi energi bangunan tergunakan untuk pencahayaan buatan, dengan pengoptimalisasian penggunaan pencahayaan alami maka persentase tersebut dapat ditekan. Masalah yang kemudian muncul adalah tentang kenyamanan visual yang ditimbulkan oleh pencahayaan alami dalam ruang. Pengguna bangunan pada dasarnya menghendaki adanya pencahayaan alami. Sebuah review pada reaksi pengguna terhadap lingkungan dalam bangunan menyatakan bahwa tersedianya pencahayaan alami secara optimal sangat diinginkan karena memenuhi dua kebutuhan dasar manusia: kebutuhan visual untuk melihat baik bidang kerja maupun ruangan dan untuk mengalami stimulasi lingkungan dari efek pencahayaan tersebut (Boyce, 1998 dalam IEA, 2000).

Kantor sebagai area kerja membutuhkan tingkat kenyamanan pencahayaan alami yang memadai agar pengguna di dalamnya dapat melakukan aktivitas dengan lancar dan memiliki produktivitas kerja yang baik. Kenyamanan visual dapat tercapai jika poin-poin kenyamanan visual teraplikasikan secara optimal antara lain dengan kesesuaian rancangan dengan standar terang yang direkomendasikan dan penataan layout ruangan yang sesuai dengan distribusi pencahayaan. Namun mendasarkan penilaian kenyamanan hanya pada standar yang direkomendasikan belum cukup, karena pengguna bangunan sebagai subjek yang merasakan kenyamanan memiliki perilaku yang berbeda tiap individu yang mempengaruhi persepsi mereka terhadap kenyamanan pencahayaan alami dalam ruang. Penilaian kenyamanan visual dari pencahayaan alami akan tepat jika terdapat kesesuaian antara hasil terukur dari kesesuaian rancangan dengan teori dan standar dengan persepsi penggunanya.

\section{Bahan dan Metode}

\subsection{Tinjauan Pustaka}

2.1.1 Cahaya Dan Terang Alami

Cahaya matahari yang masuk ke dalam bangunan dapat dibedakan menjadi tiga (Szokolay et al, 2001), yaitu:

1. Cahaya matahari langsung

2. Cahaya difus dari terang langit

3. Cahaya difus dari pantulan tanah atau bangunan lainnya

Pada kondisi iklim tropis, cahaya matahari langsung harus selalu dihindari karena membawa panas masuk ke dalam bangunan, caranya dapat melalui desain bentuk bangunan dan elemen pembayangan (shading devices) baik yang bergerak maupun yang tetap. Komponen pencahayaan yang dapat digunakan yaitu komponen 2 dan 3. Intensitas cahaya difus dari terang langit bervariasi bergantung pada kondisi terang langit (cerah atau berawan). Cahaya difus dari pantulan tanah atau bangunan lain dapat menyebabkan masalah kesilauan karena sudut datangnya yang rendah, tetapi merupakan solusi paling baik untuk kawasan iklim tropis dan sub-tropis.

\subsubsection{Sistem Pencahayaan Alami Pada Bangunan}

Secara umum, cahaya alami didistribusikan ke dalam ruangan melalui bukaan di saping (side lighting), bukaan di atas (top lighting), atau kombinasi keduanya. Tipe bangunan, 
ketinggian, rasio bangunan dan tata massa, dan keberadaan bangunan lain di sekitar merupakan pertimbangan-pertimbangan pemilihan strategi pencahayaan (Kroelinger, 2005).

Sistem pencahayaan samping (side lighting) merupakan sistem pencahayaan alami yang paling banyak digunakan pada bangunan. Selain memasukkan cahaya, juga memberikan keleluasaan view, orientasi, konektivitas luar \& dalam, dan ventilasi udara. Posisi jendela pada dinding dapat dibedakan menjadi 3: tinggi, sedang, rendah, yang penerapannya bedasarkan kebutuhan distribusi cahaya dan sistem dinding. Strategi desain pencahayaan samping yang umum digunakan antara lain:

- Single side lighting, bukaan di satu sisi dengan intensitas cahaya searah yang kuat, semakin jauh jarak dari jendela intensitasnya semakin melemah

- Bilateral lighting, bukaan di dua sisi bangunan sehingga meningkatkan pemerataan distribusi cahaya, bergantung pada lebar dan tinggi ruang, serta letak bukaan pencahayaan.

- Multilateral lighting, bukaan di beberapa lebih dari dua sisi bangunan, dapat mengurangi silau dan kontras, meningkatkan pemerataan distribusi cahaya pada permukaan horizontal dan vertikal, dan memberikan lebih dari satu zona utama pencahayaan alami.

- Clerestories, jendela atas dengan ketinggian $210 \mathrm{~cm}$ di atas lantai, merupakan strategi yang baik untuk pencahayaan setempat pada permukaan horizontal atau vertikal. Perletakan bukaan cahaya tinggi di dinding dapat memberikan penetrasi cahaya yang lebih dalam ke dalam bangunan.

- Light shelves, memberikan pembayanganuntuk posisi jendela sedang, memisahkan kaca untuk pandangan dan kaca untuk pencahayaan. Bisa berupa elemen eksternal, internal, atau kombinasi keduanya.

- Borrowed light, konsep pencahayaan bersama antar dua ruangan yang bersebelahan, misalnya pencahayaan koridor yang didapatkan dari partisi transparan ruang di sebelahnya.

\subsubsection{Faktor Pencahayaan Alami Siang Hari}

Faktor pencahayaan alami siang hari adalah perbandingan tingkat pencahayaan pada suatu titik dari suatu bidang tertentu di dalam suatu ruangan terhadap tingkat pencahayaan bidang datar di lapangan terbuka yang merupakan ukuran kinerja lubang cahaya ruangan tersebut. Faktor pencahayaan alami siang hari terdiri dari 3 komponen meliputi:

1. Sky component (SC), yaitu komponen pencahayaan langsung dari cahaya langit

2. Externally reflected component (ERC), yaitu komponen pencahayaan yang berasal dari refleksi benda-benda yang berada di sekitar bangunan yangbersangkutan.

3. Internally reflected component (IRC), yaitu komponen pencahayaan yang berasal dari refleksi permukaan-permukaan dalam ruangan.

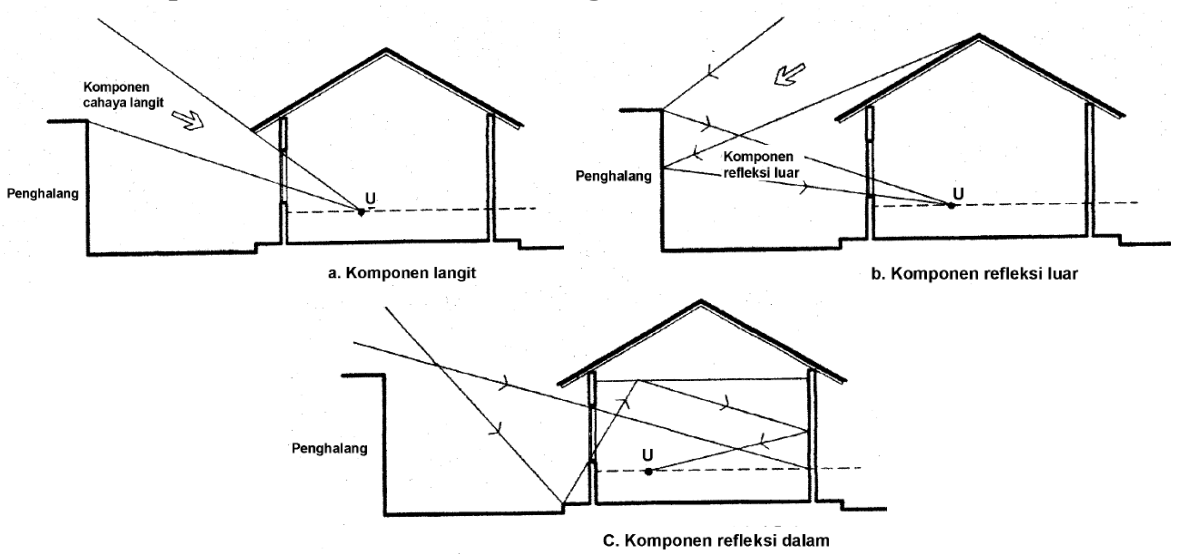

Gambar 1: Tiga Komponen cahaya langit yang sampai pada suatu titik di bidang kerja Sumber: SNI 03-2001, Tata cara perancangan sistem pencahayaan alami pada bangunan gedung 


\subsubsection{Persyaratan Tingkat Pencahayaan Dalam Ruangan}

Tabel 1: Tingkat pencahayaan rata-rata yang direkomendasikan

\begin{tabular}{|c|c|}
\hline Fungsi ruangan & $\begin{array}{c}\text { Tingkat } \\
\text { pencahayaan } \\
\text { (Lux) }\end{array}$ \\
\hline \multicolumn{2}{|l|}{ Perkantoran : } \\
\hline Ruang Direktur & 350 \\
\hline Ruang kerja & 350 \\
\hline Ruang komputer & 350 \\
\hline Ruang rapat & 300 \\
\hline Ruang gambar & 750 \\
\hline Gudang arsip & 150 \\
\hline Ruang arsip aktif & 300 \\
\hline \multicolumn{2}{|l|}{ Lembaga Pendidikan : } \\
\hline Ruang kelas & 250 \\
\hline Perpustakaan & 300 \\
\hline Laboratorium & 500 \\
\hline Ruang gambar & 750 \\
\hline Kantin & 200 \\
\hline
\end{tabular}

Sumber: SNI 03-2000, Konservasi Energi Sistem Pencahayaan pada Bangunan Gedung

\subsection{Metode Penelitian}

Jenis penelitian yang akan dilakukan adalah deskriptif dan korelasional. Tipe ini dipilih sehubungan dengan gagasan penelitian yang bermaksud mengevaluasi karakteristik dan hubungan antara rancangan pencahayaan alami dan persepsi pengguna bangunan kantor.

Lokasi objek penelitian adalah Gedung Dekanat Fakultas Teknik Universitas Brawijaya, Jl. Mayjend. Haryono No. 167, Malang, terdiri atas 8 lantai, fungsi sebagai kantor. Gedung digunakan mulai pukul 08.00-16.00, sehingga memenuhi kriteria untuk digunakan sebagai objek studi kenyamanan visual dengan pencahayaan alami.

Metode Pengumpulan Data yaitu setiap lantai bangunan (tidak termasuk lantai 7 dan 8) dipilih minimal dua ruang. Ruang-ruang sampel dipilih yang berlokasi di sisi utara bangunan dengan pertimbangan sisi utara adalah area ruang-ruang utama sedangkan sisi selatan adalah ruang utilitas. Total terdapat 12 ruang sampel dengan rincian sebagai berikut:

- Lantai 1 : 1 ruang (R. administrasi)

- Lantai 2 : 1 ruang (R. serbaguna)

- Lantai 3 : 2 ruang (R. rapat pimpinan \& R. IT)

- Lantai 4 : 3 ruang (R. jurnal, R. rapat, dan R. BPP)

- Lantai 5 : 2 ruang (R. kemahasiswaan \& R. kelas)

- Lantai 6 : 3 ruang (R. kasubag \& staf keuangan, kepegawaian, dan perlengkapan)

Pemilihan sampel responden dilakukan dengan kriteria responden adalah pengguna tetap ruangan, jumlah responden adalah 30\% penghuni ruang. Secara garis besar, data yang dikumpulkan meliputi kondisi terang alami bangunan (building condition), penggunaan bangunan (building use), dan persepsi pengguna. Variabel yang digunakan dalam pengamatan kondisi terang alami bangunan meliputi:

1. Unsur-unsur pembentuk lubang cahaya (meliputi bentuk dan dimensi jendela, orienstasi, shading device, jarak bebas dan ketinggian bangunan terdekat, vegetasi di sekitar jendela, ketinggian ruangan);

2. Unsur-unsur penyebaran cahaya alami didalam ruangan (meliputi kedalaman ruangan, unsur pemantul, penerus, dan penyerap cahaya, penutup lantai, karakteristik dinding dan plafond);

3. Furniture didalam ruangan (meliputi almari, meja kerja, kursi, rak buku);

4. Aktivitas pemakai ruangan (meliputi prosesesi, lintasan aktivitas, peletakan dokumen, kebiasaan duduk, membuka gorden jendela, dan masa/lama beraktivitas didalam ruangan) 


\section{Hasil dan Pembahasan}

\subsection{Analisa Rancangan Pencahayaan Alami dan Respon Pengguna}

Kualitas rancangan pencahayaan alami diamati melalui pengamatan dan pengukuran langsung di lapangan dan pembagian kuesioner untuk mengetahui respon pengguna terhadap ruang. Pengambilan data di lapangan ini dilakukan pada 12-19 Juni 2012 antara pukul 08.00 16.00.

Dari hasil pengamatan lapangan dan pengukuran tingkat iluminasi ruang didapatkan rancangan pencahayaan alami berada pada ambang cukup - kurang. Pada rancangan pencahayaan alami kurang, tingkat iluminasi kurang atau jauh melebihi standar yang ditetapkan SNI 03-2000 tentang Konservasi Energi Sistem Pencahayaan pada Bangunan Gedung serta terdapat berkas sinar matahari langsung yang masuk ke dalam ruangan. Pada kondisi rancangan pencahayaan alami cukup, tingkat iluminasi memenuhi standar namun masih terdapat sinar matahari langsung masuk ke dalam ruangan. Hal ini disebabkan jendela pada beberapa ruang tidak dilengkapi dengan elemen pembayangan (shading device). Kurangnya kecemerlangan pada beberapa ruang lantai 1-3 dapat dipahami sebagai akibat dari pembayangan bangunan di sekitarnya (bangunan 3 lantai gedung Arsitektur di sisi barat dan gedung PWK-Pengairan di sisi timur).

Respon pengguna terhadap ruang beragam dari positif hingga negatif, mayoritas memberikan respon sedang (cukup sesuai dengan kenyamanan pengguna). Beberapa respon kontradiktif terhadap hasil pengamatan dan pengukuran, namun dapat dipahami karena pengguna telah mengadaptasi dan memodifikasi kondisi ruangnya (melalui tata perabot) sehingga tetap dapat merasa nyaman dalam ruang yang kurang pencahayaan alaminya.

\subsection{Analisa Korelasional Rancangan Pencahayaan Alami dan Respon Pengguna}

Analisa korelasional menjelaskan hubungan antara persepsi pengguna ruangan terhadap kondisi terang alami ruangannya. Tabel 3 menunjukkan bahwa 9 dari 12 ruangan sampel menunjukkan kondisi terang alami yang kurang nyaman, sedangkan 3 ruangan cukup nyaman.

Tabel 2. Korelasi rancangan pencahayaan alami dan respon pengguna

\begin{tabular}{|c|c|c|c|c|c|}
\hline Lantai & $\begin{array}{l}\text { Posisi } \\
\text { ruang }\end{array}$ & Sampel ruangan & $\begin{array}{l}\text { Pengamatan lap. \& } \\
\text { pengukuran }\end{array}$ & $\begin{array}{l}\text { Respon } \\
\text { pengguna }\end{array}$ & Kesimpulan \\
\hline 1 & $\begin{array}{l}\text { Utara- } \\
\text { timur }\end{array}$ & R. administrasi & kurang & positif & $\begin{array}{l}\text { Kurang } \\
\text { nyaman }\end{array}$ \\
\hline 2 & Utara & R. serbaguna & kurang & negatif & $\begin{array}{l}\text { Kurang } \\
\text { nyaman }\end{array}$ \\
\hline \multirow[t]{2}{*}{3} & $\begin{array}{l}\text { Utara- } \\
\text { timur }\end{array}$ & R. rapat pimpinan & kurang & sedang & $\begin{array}{l}\text { Kurang } \\
\text { nyaman }\end{array}$ \\
\hline & $\begin{array}{l}\text { Utara- } \\
\text { barat }\end{array}$ & R. TI & kurang & positif & $\begin{array}{l}\text { Kurang } \\
\text { nyaman }\end{array}$ \\
\hline \multirow[t]{3}{*}{4} & $\begin{array}{l}\text { Utara- } \\
\text { timur }\end{array}$ & R.BPP & kurang & sedang & $\begin{array}{l}\text { Kurang } \\
\text { nyaman }\end{array}$ \\
\hline & $\begin{array}{l}\text { Utara- } \\
\text { tengah }\end{array}$ & R. rapat & cukup & sedang & Cukup nyaman \\
\hline & $\begin{array}{l}\text { Utara- } \\
\text { barat }\end{array}$ & R. jurnal & kurang & sedang & $\begin{array}{l}\text { Kurang } \\
\text { nyaman }\end{array}$ \\
\hline \multirow[t]{2}{*}{5} & $\begin{array}{l}\text { Utara- } \\
\text { timur }\end{array}$ & $\begin{array}{l}\text { R. Kasubag \& staf } \\
\text { akademik }\end{array}$ & kurang & sedang & $\begin{array}{l}\text { Kurang } \\
\text { nyaman }\end{array}$ \\
\hline & $\begin{array}{l}\text { Utara- } \\
\text { tengah }\end{array}$ & R. kelas & kurang & sedang & $\begin{array}{l}\text { Kurang } \\
\text { nyaman }\end{array}$ \\
\hline \multirow[t]{2}{*}{6} & $\begin{array}{l}\text { Utara- } \\
\text { timur }\end{array}$ & $\begin{array}{l}\text { R. Kasubag \& staf } \\
\text { perlengkapan }\end{array}$ & cukup & sedang & Cukup nyaman \\
\hline & Utara- & R. Kasubag \& staf & kurang & positif & Kurang \\
\hline
\end{tabular}




\begin{tabular}{|l|l|l|l|l|l|}
\hline & tengah & kepegawaian & & & nyaman \\
\hline $\begin{array}{l}\text { Utara- } \\
\text { barat }\end{array}$ & $\begin{array}{l}\text { R. Kasubag \& staf } \\
\text { keuangan }\end{array}$ & cukup & sedang & Cukup nyaman \\
\hline
\end{tabular}

\section{Simpulan}

Pencahayaan alami pada Gedung Dekanat FT UB dicapai dengan menggunakan tipe side-lighting dengan jendela pada sisi dinding utara, timur, atau barat ruangan. Ruang-ruang di Gedung Dekanat FT UB mayoritas kurang nyaman secara visual, hanya beberapa saja yang sudah cukup nyaman secara visual. Tidak ada ruang yang terkategorikan sangat nyaman secara visual.

Hasil pengukuran dan pengamatan lapangan menunjukkan kondisi terang alami beragam antara kurang - cukup, disebabkan standar iluminasi yang tidak sesuai standar iluminasi yang dipersyaratkan SNI 03-2000 tentang Konservasi Energi Sistem Pencahayaan pada Bangunan Gedung maupun karena adanya berkas sinar matahari langsung yang mausk ke dalam ruang. Respon pengguna terhadap kualitas kenyamanan visual ruang beragam dari positif - negatif dengan mayoritas pengguna memberikan respon sedang (cukup sesuai dengan kenyamanan pengguna).

Rekomendasi untuk mendukung kenyamanan visual dapat dicapai dengan modifikasi pada ruang, dapat berupa modifikasi interior maupun eksterior. Modifikasi interior dapat berupa penataan kembali layout ruang dan pola tata perabot, penambahan reflektor cahaya dalam ruang, atau dengan menggunakan bantuan pencahayaan buatan. Modifikasi eksterior dapat dengan menambahkan shading device (elemen pembayangan), memperbesar luasan jendela, atau menambahkan skylight.

\section{Daftar Pustaka}

IEA (International Eergy Agency). 2000. Daylight in Bildings; A Source Book on Daylighting Systems and Components. The Lawrence Berkeley National Library: California.

Kerr, Thor. 2008. The Green Future of Buildings. Futurarc Magazine, 3rd quarter, volume 10. Jakarta: PT BCI Asia Construction Information Pte Ltd

Kroelinger, Michael D. 2005. Daylight in Bildings. Dimuat dalam Implications Vol 03 Issue 3, www.informedesign,umn.edu. Diakses pada 28 Februari 2012.

Lechner Norbert. 2007 Heating, Cooling, Lighting, Design Method for Architects, Jakarta ; PT.Rajagrafindo Persada.

SNI 03-6197-2000 tentang Konservasi Energi Sistem Pencahayaan pada Bangunan Gedung. Badan Standardisasi Nasional.

SNI 03-2396-2001 tentang Tata Cara Perancangan Sistem Pencahayaan Alami pada Bangunan Gedung. Badan Standardisasi Nasional.

Szokolay, S.V., Arvind Krishan, Nick Baker, dan Simon Yannas. 2001. Climate Responsive Architecture; A Design handbook for Energy Efficient Building. New Delhi: Tata McGrawHill Publishing Co.Ltd

Suwantoro, Hajar. 2006 Pencahayaan Alami pada Ruang Kuliah Labtek IXB Jurusan Teknik Arsitektur ITB. Departemen Arsitekrtur Fakultas Teknik Universitas Sumatra Utara.

Thojib, Jusuf. 1992. Kajian RancanganPencahayaan Alami dan Persepsi Pemakai pada Bangunan Kampus. Thesis. Jurusan Teknik Arsitektur Program Pascasarjana Institut Teknologi Bandung. 